\title{
An influence of track stiffness discontinuity on pantograph base vibrations and catenary- pantograph dynamic interaction
}

https://doi.org/10.2478/sgem-2019-0035

received August 20, 2019; accepted November 3, 2019.

\begin{abstract}
In this article, the computational methodology of the catenary-train-track system vibration analysis is presented and used to estimate the influence of vehicle body vibrations on the pantograph-catenary dynamic interaction. This issue is rarely referred in the literature, although any perturbations appearing at the pantographcatenary interface are of great importance for highspeed railways. Vehicle body vibrations considered in this article are induced by the passage of train through the track stiffness discontinuity, being a frequent cause of significant dynamic effects. First, the most important assumptions of the computational model are presented, including the general idea of decomposing catenarytrain-track dynamic system into two main subsystems and the concept of one-way coupling between them. Then, the pantograph base vibrations calculated for two train speeds $(60 \mathrm{~m} / \mathrm{s}, 100 \mathrm{~m} / \mathrm{s})$ and two cases of track discontinuity (a sudden increase and a sudden decrease in the stiffness of track substrate) are analyzed. Two cases of the railway vehicle suspension are considered - a typical two-stage suspension and a primary suspension alone. To evaluate catenary-pantograph dynamic interaction, the dynamic uplift of the contact wire at steady arm and the pantograph contact force is computed. It is demonstrated that an efficiency of the two-stage suspension grows with the train speed; hence, such vehicle suspension effectively suppresses strong sudden shocks of vehicle body, appearing while the train passes through the track stiffness discontinuity at a high speed. In a hypothetical
\end{abstract}

\footnotetext{
*Corresponding author: Danuta Bryja, Department of Bridges and Railways, Faculty of Civil Engineering, Wroctaw University of Science and Technology, Wybrzeże Wyspiańskiego 27, 50-370 Wrocław, Poland, E-mail: danuta.bryja@pwr.edu.pl

Adam Hyliński, Department of Bridges and Railways, Faculty of Civil Engineering, Wrocław University of Science and Technology, Wybrzeże Wyspiańskiego 27, 50-370 Wrocław, Poland
}

case when the one-stage vehicle suspension is used, the pantograph base vibrations may increase the number of contact loss events at the catenary-pantograph interface.

Keywords: catenary-train-track system, track stiffness discontinuity, railway vehicle suspension, vibration simulations, catenary-pantograph dynamic interaction.

\section{Introduction}

Along with the development of high-speed railways, a lot of articles on the dynamics of railway system structural elements appeared in the literature. Many of those articles are devoted to computational methods for simulating coupled vibrations of the track-train system [1-3] as well as the vibrations of catenary-pantograph system [4-6]. However, while there is an extensive literature coverage treating both systems separately, the research on the whole railway system covering the flexible track with the moving train together with the catenary is poorly developed. This results mainly from difficulties in modeling such complicated system, accounting for the dynamic interaction at the contact between railway vehicle and infrastructure. In the case of high-speed trains, this contact occurs in two groups of places: between vehicle wheels and rails and between collector heads of pantographs and the contact wire of catenary. As it is stated by Ambrósio et al. and Pombo et al. [7-9], the dynamic phenomena occurring at these places become more and more significant with the growing speed of trains. They influence the operational conditions of highspeed railways - especially the quality of current collection through the catenary-pantograph interface. There are many articles dealing with an analysis of dynamic interaction between the pantograph and catenary because it allows to evaluate the quality of current collection by the numerical prognosis of the number of loss of contact events [4-7, 10]. However, in a great majority, their authors 
assume that the pantograph base is immovable in a vertical direction, although in reality, it undergoes vertical vibrations as part of a running vehicle. It is difficult to find an article where an impact of vehicle vibration on the pantograph-catenary dynamic interaction is considered. The article by Pombo and Ambrosio [11] is an exception, but it considers only one scenario, in which the vehicle vibrations are induced by geometrical irregularities of rails, measured experimentally. Considering that in the case of high-speed railways the rails are of really good quality, their irregularities can induce only slight vehicle vibrations which have a negligible effect on the catenary.

The main objective of this paper is an attempt to identify such a train passage scenario where railway vehicle vibrations result in worsening the quality of pantograph-catenary dynamic interaction and, thus, the conditions of a current collection. For this purpose, the comprehensive computational method for the vibration simulation of the combined catenary-train-track system is proposed. The method is specifically aimed at the analysis of the catenary vibrations induced by moving pantograph, accounting for vertical oscillation of the pantograph base. As the most probable scenario in which the pantograph base vibrations can influence the pantograph-catenary dynamic interaction, the train passage through the track discontinuity having the form of a sudden change in stiffness of the track substrate is considered in the article.

The proposed computational method combines two methods developed earlier by the authors and dedicated for separate vibration analysis of two systems: pantograph and catenary system and railway track and vehicle system. The first method, referring to the catenary-pantograph vibrations, has been widely described [12-15]. Its original feature is the consistent use of the theory of flexible cables in order to describe vibrations of catenary main structural elements, that is, the messenger wire and the contact wire. The validity of this method has been confirmed by a positive result of the numerical validation conducted in accordance with the European standard EN 50318 [16]. It is worth noting that in recent literature, the cable theory is very rarely used for modeling the catenary, despite the cable nature of catenary main elements. In general, different commercial software are commonly applied, where the finite element method (FEM) catenary models are created with the use of beam elements characterized by very low flexural stiffness and subjected to axial forces. A synthetic overview of various methods for modeling the catenary can be found in Pombo et al. [9] and Poetsch et al. [10].
The second method, which refers to the track-train system, is intended for analysis of vibrations induced by a train passage through the track stiffness discontinuity $[17,18]$. It assumes that the railway track is the EulerBernoulli beam resting on a viscoelastic foundation of the Winkler type, and the railway vehicle is a multibody system where wheelsets, bogie frames, and a car body are distinguished. The track with a sudden discontinuity of substrate stiffness is discretized by the Galerkin FEM (GFEM).

The vibration simulation procedure of the catenarytrain-track system, created on the basis of two abovementioned methods, has been briefly described by Bryja and Popiołek [19] and used for an initial numerical analysis. In this article, the most important assumptions of the assumed computational model will be presented, including a general idea of the catenary-train-track dynamic system decomposition into two main subsystems and the concept of one-way coupling between them [20]. Then, time histories of the pantograph base vertical vibrations obtained for two train speeds $(60 \mathrm{~m} / \mathrm{s}, 100 \mathrm{~m} / \mathrm{s})$ and two cases of track discontinuity (i.e., a sudden increase and a sudden decrease in the track substrate stiffness) will be shown, and next, their influence on the catenarypantograph dynamic interaction will be examined. In addition, two cases of the railway vehicle suspension will be considered - a typical two-stage suspension and a primary suspension alone (between wheelsets and bogie frames). To evaluate the catenary-pantograph dynamic interaction, the dynamic uplift of the contact wire at a steady arm and the contact force exerted on the contact wire by the pantograph head will be analyzed.

\section{Computational model and simulation method}

\subsection{General description of the catenary- train-track system}

The simulation method used in this article assumes the decomposition of the catenary-train-track system into two main subsystems: (A) catenary and pantographs and (B) track and train. The physical contact between them is the pantograph base fixed rigidly to the vehicle roof. Each of the highlighted main subsystems (A) and (B), in accordance with its name, consists of two internal subsystems, and these, in turn, consist of many elements which are shown in Fig. 1. 


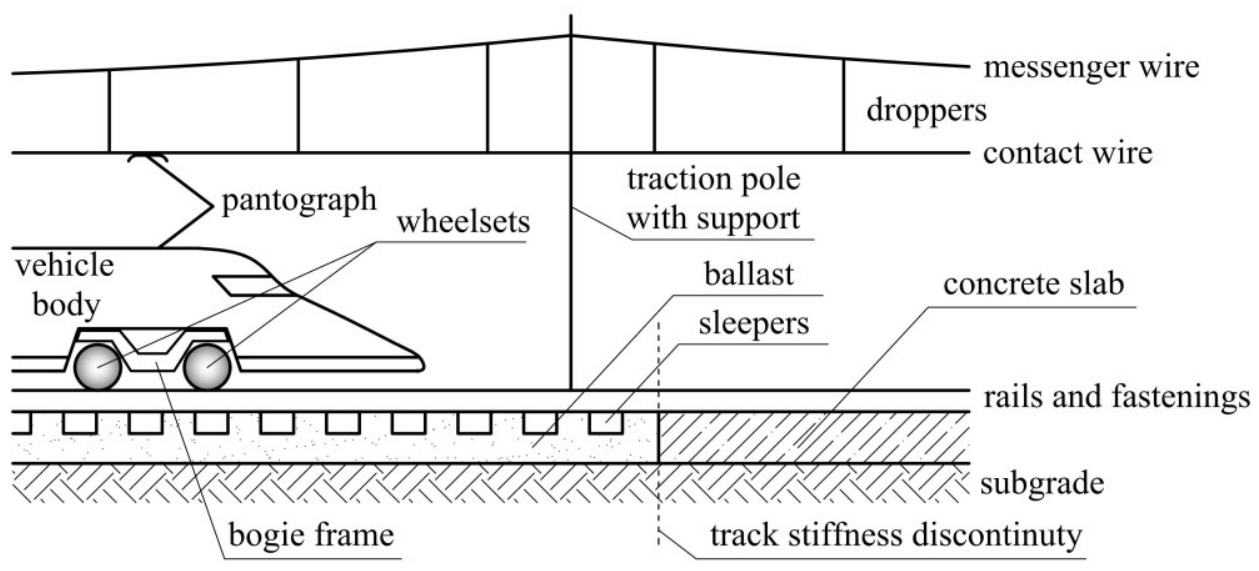

Figure 1: Scheme of catenary-train-track system with distinctive particular elements.

It is assumed that the contact between main subsystems (A) and (B) is modeled by the use of one-way coupling method which is often applied in the fluidstructure computational mechanics, for instance [20]. For one-way coupling calculations of the fluid-structure interaction, the fluid affects the structure motion but the motion of structure does not affect fluid properties. Similarly, it is assumed for the considered catenarytrain-track system that the pantograph base motion affects the catenary-pantograph subsystem, constituting a kinematic excitation of the pantograph vibrations, but this does not occur reversely. Vibrations of the catenarypantograph subsystem are not transferred to the traintrack subsystem because they do not significantly affect a heavy railway vehicle. This approach, that is, the use of one-way coupled simulations is consistent with the physical behavior of the considered system and gives a possibility for reducing the computational effort.

In each main subsystem: (A) catenary and pantographs or (B) track and train, two internal subsystems are coupled in a two-way manner [20], excluding the moments when the loss of contact occurs. The contact loss is manifested by detaching the collector head from the contact wire (in (A)) or the wheel from the rail (in (B)). Hence, for a moment, there is no transmission of vibrations between internal subsystems in the given main subsystem. Loss of contact is the source of specific geometrical non-linearity in the main subsystems. A similar type of non-linearity occurs in the main subsystem (A) due to droppers' behavior, because droppers do not transfer a compression. This problem is described in detail $[4,14,15]$. In the presented simulation method, the geometrical non-linearities due to the loss of contact between internal subsystems are neglected, similarly as in many publications by other authors $[4,5$,
7], while the non-linearity caused by droppers' behavior is accounted for.

The most significant simplifications of the assumed computational model are as follows: (1) the model is a flat one (two-dimensional) and (2) the complex internal structure of the railway track is replaced by the Euler beam resting on the homogeneous viscoelastic foundation. The first simplification is acceptable because the vertical motion is the dominant vibration component of the considered catenary-train-track system; hence, a flat model is sufficient enough to fulfill the objective of the article which is to assess the impact of a train passage through the track stiffness discontinuity on catenary vibrations. The second simplification which consists of omitting the internal structure of the track is also justified because, from the research purpose viewpoint, the very fact of an occurrence of track stiffness discontinuity is important - not the nature of it.

\subsection{The main subsystem (A): catenary and pantographs}

The assumed dynamic model of the main subsystem (A), shown schematically in Fig. 2, is described in detail in earlier published papers $[13,14]$. Compared with the solutions presented in the literature, the model stands out by the consistent application of the theory of cable vibrations in order to formulate partial differential equations governing the motion of messenger and contact wires. An original feature of this model is also the method for considering the non-linear behavior of droppers.

The model of the main subsystem (A) is referred to as the catenary which consists of one contact wire and one 


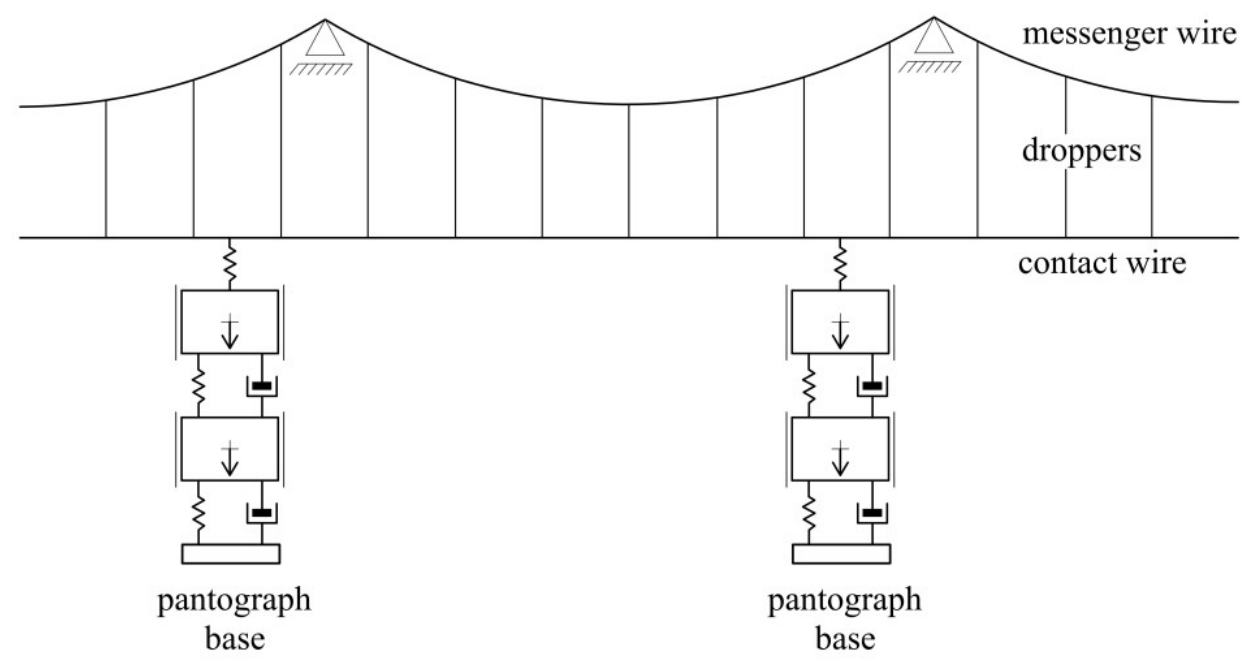

Figure 2: Dynamic model of the catenary- pantographs subsystem.

messenger wire. The catenary section being analyzed is composed of a given number of spans. The messenger wire, supported slidingly on rigid supports, is represented by a multispan flexible cable with a parabolic route within each span (in an unloaded state). The contact wire is treated as a straight cable (string) which is suspended to messenger wire by flexible droppers modeled by nonlinear elastic constraints (springs). Messenger wire and contact wire are tensed by different constant static forces.

Pantographs are modeled by two-degree-of-freedom dynamic systems. Contact between the pantograph collector head and the contact wire is represented by a linear contact spring that does not reflect a real behavior of the structure because the effects due to loss of contact are neglected in that way. However, such simplification is often applied in the literature and is allowed by the European standard EN 50318 [16] which gives guidelines for vibration simulation methods of the pantographcatenary system. In the presented model, the loss of contact is identified by a negative value of the contact force.

Equations of motion of the catenary-pantographs subsystem have been derived based on the Lagrange equations, using the Ritz approximation method for the catenary, as shown in Bryja and Prokopowicz [13]. They may be written in matrix notation:

$$
\begin{gathered}
\mathbf{B}_{(\mathrm{A})} \ddot{\mathbf{q}}_{(\mathrm{A})}(t)+\mathbf{C}_{(\mathrm{A})} \dot{\mathbf{q}}_{(\mathrm{A})}(t)+ \\
{\left[\mathbf{K}_{\text {const }}+\widehat{\mathbf{K}}_{\text {const }}-(1-\kappa) \widehat{\mathbf{K}}_{\mathrm{dc}}\left(\mathbf{q}_{(A)}\right)+\widetilde{\mathbf{K}}(t)\right]_{(A)} \mathbf{q}_{(A)}(t)=\mathbf{f}_{(A)}(t)}
\end{gathered}
$$

where an explicit form of the inertia, damping, and stiffness matrices, as well as the vector of excitation forces, can be found in Bryja and Prokopowicz [13] and Bryja and Hyliński [14]. The excitation forces gathered in the vector $f_{(A)}(t)$ depend on the static contact forces of pantographs, moving along the catenary at the constant speed. Dynamic increments in the moving contact forces, being a measure of dynamic interaction between pantographs and contact wire, are included in the timedependent stiffness matrix component: $[\tilde{\mathbf{K}}(t)]_{(\mathrm{A})} \mathbf{q}_{(\mathrm{A})}(t)$. In this article, the vector $\mathbf{f}_{(A)}(t)$ depends also on the dynamic displacements $W_{J}^{p}(t)$ and their velocities $\dot{W}_{J}^{p}(t)$ at contact points between the pantograph and contact wire, where $J$ denotes the pantograph number. These functions are computed by the solver of track-train subsystem.

The equations of motion (1) are non-linear due to the non-linear stiffness characteristic of droppers [14]. It is assumed that the droppers are characterized by the tensile stiffness $k_{\mathrm{t}}=k$ and the residual compressive stiffness $k_{\mathrm{c}}=\kappa k$ which value is a given small percentage of a tensile stiffness. Note, that the assumption $\kappa=0$ leads to droppers which do not carry any compression (have zero compressive stiffness). In order to take the nonlinear droppers' stiffness into account, two components related exclusively to droppers have been isolated in the general stiffness matrix: $\left[\hat{\mathbf{K}}_{\text {const }}\right]_{(\mathrm{A})}$ and $\left[\hat{\mathbf{K}}_{\mathrm{dc}}\left(\mathbf{q}_{(\mathrm{A})}\right)\right]_{(\mathrm{A})}$. Both components have the same structure and satisfy the assumption that $k_{\mathrm{c}}=k_{\mathrm{t}}=k$. The first component covers all droppers of the catenary, while the second applies only to droppers detected as being under compression at time $t$ (therefore, it depends on $\left.\mathbf{q}_{(A)}\right)$. Expression $\left[\hat{\mathbf{K}}_{\text {const }}-(1-\kappa)\right.$ $\left.\hat{\mathbf{K}}_{\mathrm{dc}}\left(\mathbf{q}_{(\mathrm{A})}\right)\right]_{(\mathrm{A})}$ reduces the stiffness of droppers subjected to compressive forces, into the value $k_{\mathrm{c}}=\kappa k$. The component $\left[\mathbf{K}_{\text {const }}\right]_{(A)}$ is related only to the elastic properties of messenger and contact wires. 


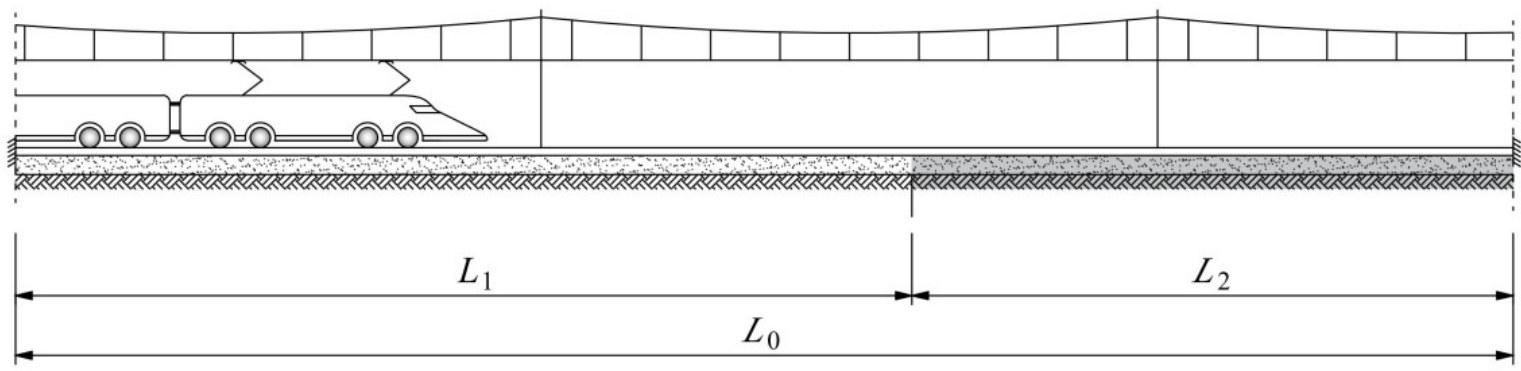

Figure 3: Schematic diagram of the track test section.

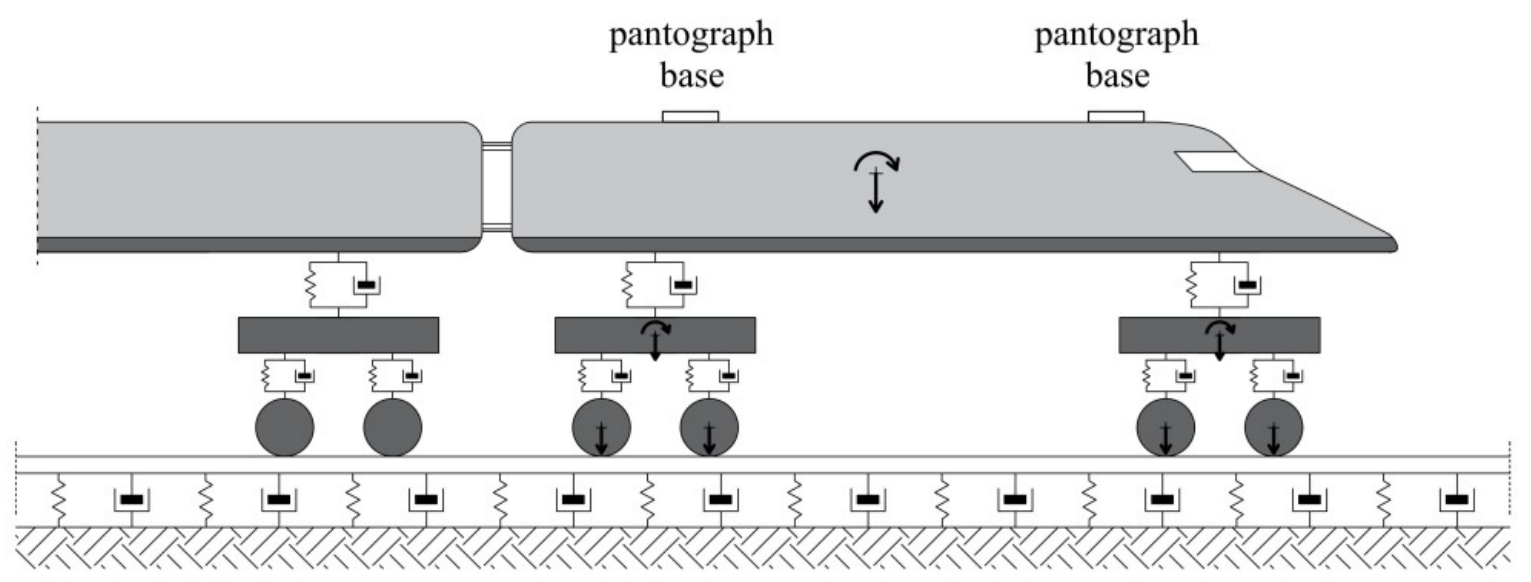

Figure 4: Dynamic model of the train-track subsystem with marking vehicle degrees of freedom.

To solve equation (1), the unconditionally stable variant of the Newmark numerical integration method is applied with the use of an iterative loop for calculating the stiffness matrix component: $\hat{\mathbf{K}}_{\mathrm{dc}}\left(\mathbf{q}_{(\mathrm{A})}\right)$, at each time step of numerical integration. The method of solving the equations of motion is described in detail in Bryja and Hyliński [14, 15]. At each time step of the simulation, the contact wire displacements at indicated points, dynamic contact force, etc, are generated based on general coordinates $\mathbf{q}_{(\mathrm{A})}\left(t_{i}\right)$ determined at time points $t_{i}$. Discrete records of resulting time histories can be further processed.

\subsection{The main subsystem (B): train and track}

The considered section of the track is straight and horizontal, as shown in Fig. 3. Its total length $L_{0}$ is divided into two segments: $L_{1}$ and $L_{2}$, due to an occurrence of the track discontinuity having the form of a sudden step change in the track stiffness. Such track stiffness discontinuities are usually of structural nature and exist along the track at such places as transitions from ballasted track to slab track (see Fig. 1) or bridge approaches, culverts, turnouts, ends of tunnels, etc. A train passage through the stiffness discontinuity of the track induces significant vibrations of vehicles and, thus, rail vibrations [21].

In the presented vibration simulation method, the track stiffness discontinuity is considered leaving aside its nature. The applied dynamic model of the train-track main subsystem is shown in Fig. 4. It is assumed that the railway track is the Euler-Bernoulli beam resting on the viscoelastic foundation of the Winkler type. To transform the generally known, partial differential equation of the beam vibrations, into equations of motion in a time domain, the GFEM has been adopted. This approach allows to easily account for the track stiffness discontinuity, by setting different stiffness and damping parameters of the Winkler foundation over two track segments $\left(L_{1}\right.$ and $\left.L_{2}\right)$. To satisfy the GFEM requirements, both ends of the whole track section $L_{0}$ have been assumed as rigidly fixed, which is shown in Fig. 3. The entire GFEM procedure adopted in this article has been explained by Bryja et al. [17, 22, 23].

It is assumed that the train is an electric trainset composed of a given number of repetitive units (vehicles), 
each based on two 2-axle bogies, as shown in Fig. 4. The trainset is equipped with a maximum of two pantographs mounted on the roof of one selected unit or two units. The pantograph base is rigidly connected with the vehicle roof, moves at constant speed together with the train, and vibrates only in a vertical direction. The assumed vehicle model of 10 degrees of freedom, presented in Fig. 4, allows to calculate vertical vibrations of the vehicle body at the pantograph attachment point. The model consists of seven rigid mass elements representing: vehicle body, two rigid bogies, and four wheelsets, connected by sets of linear springs and viscous dampers which constitute twostage vehicle suspension. It is assumed that the wheelsets remain in full contact with rails during the vibrations. As a further stage of the research, it is planned to extend the model by introducing the Hertz contact spring between wheelsets and rails that will allow accounting for the loss of contact.

The equations of motion of the described train-track subsystem derived in Bryja et al. [17, 22] on the basis of equations in Bryja et al. [23], can be written in the following general form:

$\mathbf{B}_{(\mathrm{B})}(t) \ddot{\mathbf{q}}_{(\mathrm{B})}(t)+\mathbf{C}_{(\mathrm{B})}(t) \dot{\mathbf{q}}_{(\mathrm{B})}(t)+\mathbf{K}_{(\mathrm{B})}(t) \mathbf{q}_{(\mathrm{B})}(t)=\mathbf{f}_{(\mathrm{B})}(t)$

In the simulation method, the solutions of equation (2), that is, general coordinates $\mathbf{q}_{(\mathrm{B})}(t)$, their velocities $\dot{\mathbf{q}}_{(\mathrm{B})}(t)$, and accelerations $\ddot{\mathbf{q}}_{(\mathrm{B})}(t)$ are obtained by the use of the Newmark method, and on that basis, time histories of displacements $W_{J}^{p}(t)$, velocities $\dot{W}_{J}^{p}(t)$, and accelerations $\ddot{W}_{j}^{p}(t)$ of vehicle body vibrations at the pantograph base attachment are calculated. These functions are transferred to the catenary-pantographs solver.

\section{Numerical analysis, assumptions and results}

The numerical analysis is divided into two steps, according to the assumed decomposition of the catenary-traintrack dynamic system into two main subsystems and the one-way coupling method used for vibration simulation of the whole system. In the first step, time histories of the pantograph base vibrations obtained from the track-train solver are presented and analyzed. In the second step, the corresponding catenary vibrations and the dynamic contact force of the pantograph are presented in order to evaluate the impact of vehicle vibrations on the dynamic interaction between the pantograph and catenary.

\subsection{Step 1: vehicle body vibrations}

The analysis is conducted for a hypothetical trainset consisting of eight repetitive units (vehicles) which include mass parameters, primary and secondary suspension parameters, and dimensions, which are gathered in Table 1. These parameters are taken from Bryja et al. [23]; they reflect the typical unit of Shinkansen high-speed train. The trainset is equipped with a single pantograph mounted on the first unit. A theoretical point of the pantograph base attachment lies on the vertical axis of the leading bogie. In order to find a scenario where the vehicle vibrations influence the catenary, a hypothetical vehicle equipped with a primary suspension alone is additionally considered. In the computational model, such a hypothetical vehicle is defined by setting a very high stiffness of the spring and zero damping parameter in the secondary vehicle suspension.

The calculations have been carried out for two train speeds, $60 \mathrm{~m} / \mathrm{s}$ and $100 \mathrm{~m} / \mathrm{s}$, assuming that the length of the track section is equal to $300 \mathrm{~m}$ and the track stiffness discontinuity occurs in the middle of this section. Flexural stiffness and unit mass of the Euler beam representing two rails are $1.2831 \times 10^{7} \mathrm{Nm}^{2}$ and $1.21 \times 10^{2} \mathrm{~kg} / \mathrm{m}$, respectively. Damping of the rail material is taken into account assuming the retardation time of $2.1 \times 10^{-5} \mathrm{~s}$.

Based on the experience from previous research described by Bryja and Popiołek [19], two types of track stiffness discontinuity are considered. The type 1 is a sudden 50 -fold decrease in the stiffness of the elastic Winkler foundation: from the value of $k_{\mathrm{f}}$ to $k_{\mathrm{f}} / 50$, while type 2 means the reverse transition: from the value of $k_{\mathrm{f}} / 50$ to $k_{\mathrm{f}}$, where $k_{\mathrm{f}}=1.1 \times 10^{8} \mathrm{~N} / \mathrm{m}^{2}$ is the assumed basic value of the Winkler foundation stiffness, specific for the track of a very good quality (see Esveld [21]). The damping coefficient characterizing the track foundation amounts to $2.8667 \times 10^{5} \mathrm{Ns} / \mathrm{m}^{2}$.

Simulation results of vehicle body vibrations at the point of pantograph base attachment are shown in Fig. 5 (for the track stiffness discontinuity of type 1) and Fig. 6 (for the track stiffness discontinuity of type 2). Time histories of displacement, velocity, and acceleration are presented for two cases of vehicle suspension (two-stage and singlestage suspension). The graphs on the left side relate to the passage speed of $60 \mathrm{~m} / \mathrm{s}$, those on the right side -100 $\mathrm{m} / \mathrm{s}$. These graphs are prepared on the same vertical scale for both speeds, in order to facilitate a comparison of the obtained results. Similarly, time axes are equally scaled for both speeds, so that the time nature of vibrations can be compared. A vertical dotted green line denotes the moment of passing through the track stiffness discontinuity. 
Table 1: Vehicle parameters (from Bryja et al. [23]).

$\begin{array}{lll}\begin{array}{l}\text { Mass of fully loaded vehicle } \\ \text { body }\end{array} & \begin{array}{l}3.60 \times 10^{4} \mathrm{~kg} \\ \begin{array}{l}\text { Central rotational moment of } \\ \text { the vehicle body mass }\end{array}\end{array} & \begin{array}{l}\text { Stiffness of primary suspension } \\ \text { (single spring) }\end{array} \\ \begin{array}{l}\text { Mass of the bogie } \\ \text { Damping of primary suspension } \\ \text { (single damper) } \\ \text { Sentral rotational moment of } \\ \text { the bogie mass }\end{array} & \begin{array}{l}\text { Siffness of secondary suspension } \\ \text { (single spring) }\end{array}\end{array}$

It should be recalled that both ends of the considered track section are fixed in the computational model, and the vehicle before entering the track is in a static equilibrium state (i.e., its dynamic displacements are zero). Entering on a deformable track induces vehicle body vibrations in the form of decaying oscillations which are visible in the first phase of vehicle motion, in all graphs presented in Figs. 5 and 6. This initial effect is much more intense when the vehicle enters the track resting on a weak substrate $\left(k_{\mathrm{f}} / 50\right)$ - Fig. 6. Local amplitudes of displacement, velocity, and acceleration are then compared with those that appear after the passage through the track stiffness discontinuity of type 1 (change from $k_{\mathrm{f}}$ to $k_{\mathrm{f}} / 50$ ) - Fig. 5 . This indicates that the track substrate with the elasticity coefficient $k_{\mathrm{f}}=1.1 \times 10^{8} \mathrm{~N} / \mathrm{m}^{2}$ does not differ much from a rigid foundation, as evidenced also by a weak initial effect that appears when the vehicle enters the track resting on a strong substrate $\left(k_{\mathrm{f}}\right)-$ Fig. 5 .

In the case of time histories obtained for the speed of $60 \mathrm{~m} / \mathrm{s}$, displacements of the vehicle without secondary suspension are lower than for a vehicle with two-stage suspension but velocities and accelerations are higher, which is consistent with practice. In particular, the maximum absolute value of vibration acceleration is more than twice higher in relation to the train with two-stage suspension. This effect is even greater at a speed of 100 $\mathrm{m} / \mathrm{s}$. It shows the intensity of the impulse load induced by a high-speed passage through the track stiffness discontinuity and also confirms the need to use a twostage suspension in high-speed trains. The obtained results demonstrate that the secondary suspension effectively reduces accelerations of vehicle body vertical vibrations and, thus, improves passenger comfort as well as operational conditions of the pantograph mounted on vehicle roof.

An interesting phenomenon is observed when comparing pantograph base displacements calculated for the train speed of $60 \mathrm{~m} / \mathrm{s}$ and $100 \mathrm{~m} / \mathrm{s}$. At the speed of $100 \mathrm{~m} / \mathrm{s}$, local amplitudes of vibrations of the vehicle with two-stage suspension are smaller than for one-stage suspension, contrary to the case of $60 \mathrm{~m} / \mathrm{s}$. This is caused by relatively long retardation time of the reaction of twostage suspension, due to additional dampers. Comparing the results obtained at the speed of $60 \mathrm{~m} / \mathrm{s}$ and $100 \mathrm{~m} / \mathrm{s}$, for the same two-stage suspension of the vehicle, one can conclude that this long retardation time results in decreasing the vehicle body vibrations as well as their velocities and accelerations - all local amplitudes are a bit smaller. Therefore, it is seen that a two-stage suspension efficiency increases with the train speed. The opposite effect appears for a single-stage suspension, especially in the case of vibration accelerations. The intensity of vibrations caused by a train passage through the track stiffness discontinuity is definitely higher at the speed of $100 \mathrm{~m} / \mathrm{s}$ than at $60 \mathrm{~m} / \mathrm{s}$ because exclusion of secondary suspension results in a much lower delay in the dynamic response of the vehicle body. This is in line with an engineers' intuition. All these conclusions refer to both considered types of track stiffness discontinuity. 


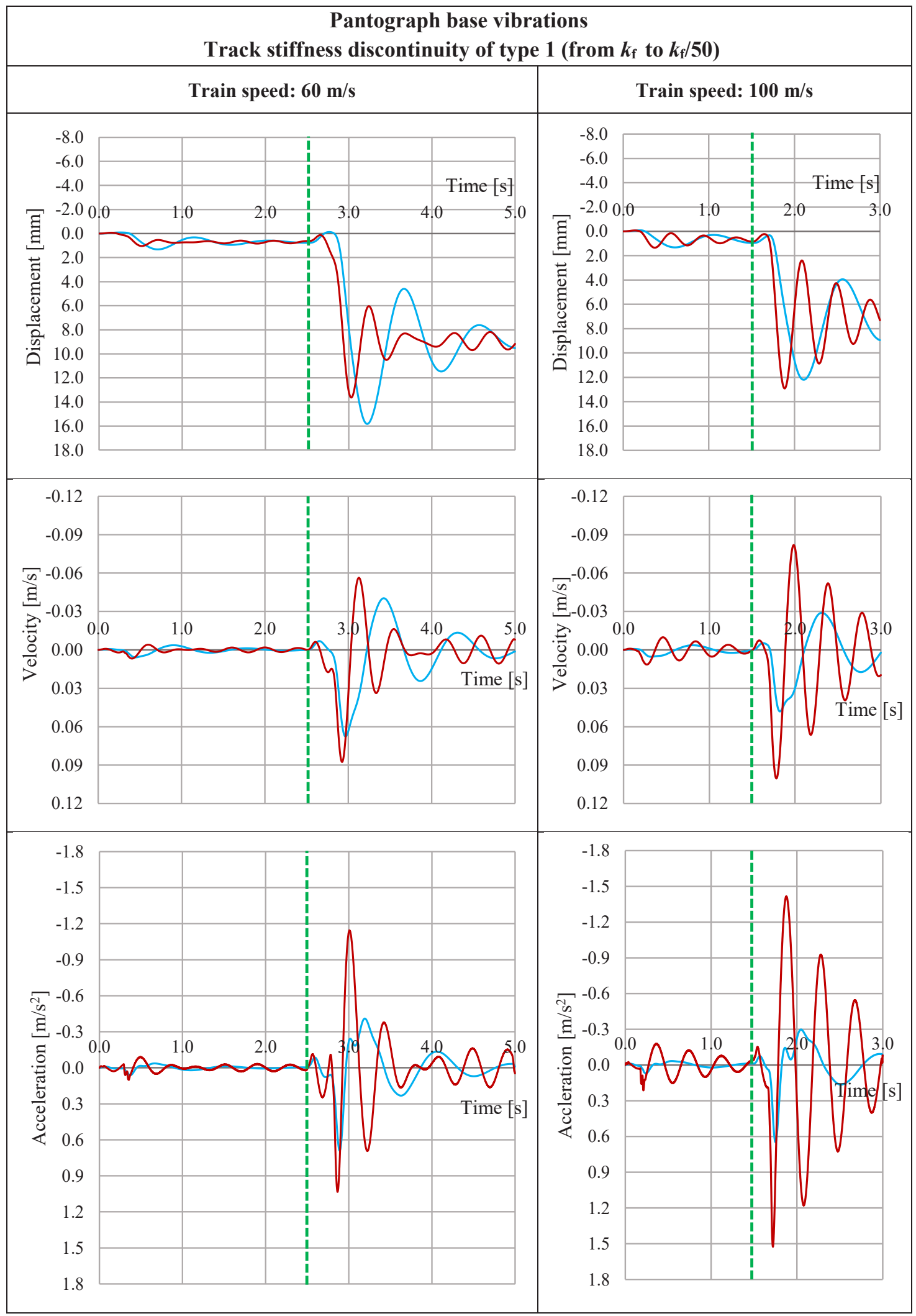

Figure 5: Displacements, velocities and accelerations of the pantograph base, during a passage through the track stiffness discontinuity, depending on the vehicle suspension: blue color line indicates vehicle with two-stage suspension and red color line indicates vehicle without secondary suspension. 


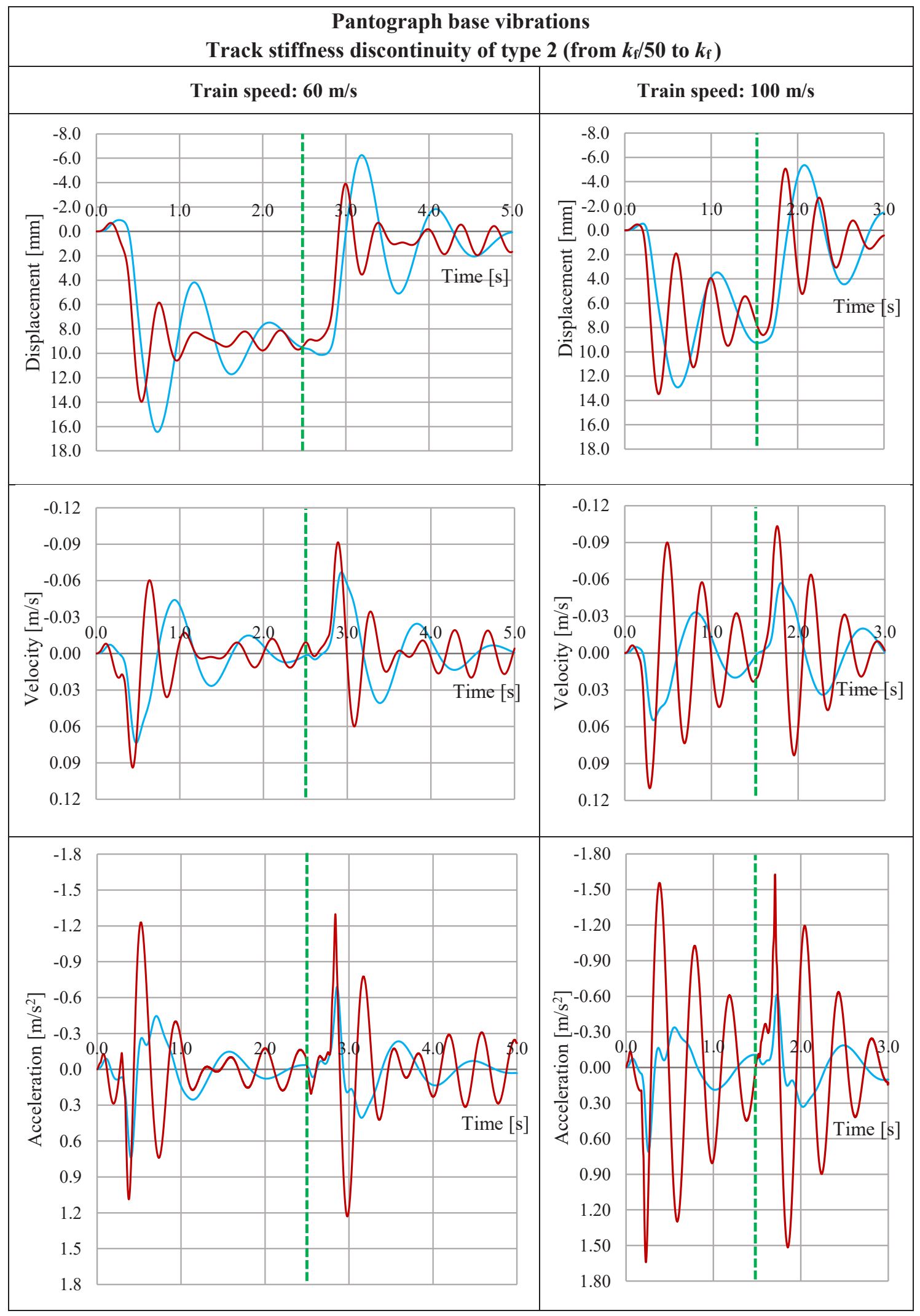

Figure 6: Displacements, velocities and accelerations of the pantograph base, during a passage through the track stiffness discontinuity, depending on the suspension parameters of the vehicle: blue color line indicates vehicle with two-stage suspension and red color line indicates vehicle without secondary suspension. 
It should be noted that the assumed track length preceding the track stiffness discontinuity (i.e., $150 \mathrm{~m}$ ) is too short as the initial vehicle body oscillation is not completely decayed, especially in the case shown in Fig. 6. Hence, the dynamic effect caused by a train passage through the track stiffness discontinuity is amplified because of overlapping the initial vibrations induced by entering the track. However, this amplification is advisable; it may help to identify such a train passage scenario in which the vibrations of a railway vehicle considerably influence the pantograph-catenary dynamic interaction. For this purpose, all solutions presented in Figs. 5 and 6 will be examined in the second step of numerical analysis.

\subsection{Step 2: catenary vibrations}

The second step of numerical analysis is devoted to an evaluation of the impact of pantograph base vertical oscillations, induced by train passages through the track stiffness discontinuity, on catenary vibrations. According to the assumed research methodology, vehicle body vibrations at the pantograph base attachment point, obtained in the first step of numerical analysis, have been transferred to the solver of pantograph-catenary subsystem, constituting the kinematical excitation of the pantograph vibrations. While simulating the pantographcatenary vibrations, the time step of numerical integration of equations of motion has been taken the same as the time step of recording the simulation results obtained from the train-track solver.

It is assumed that the test section of the catenary consists of five identical spans with a length of $60 \mathrm{~m}$ each, which gives a total length of $300 \mathrm{~m}$ being equal to the length of the track section considered. The material and geometric characteristics of the catenary structural elements and pantograph parameters are summarized in Table 2.

To analyze the catenary vibrations, the contact wire uplift at the right steady arm of the middle catenary span is examined, due to the localization directly behind the place where the stiffness discontinuity appears in the track. In turn, the dynamic interaction between the pantograph and catenary is analyzed based on time histories of the pantograph contact force. The simulation results for different scenarios of a train passage are presented in Figs. 7 and 8, following the pantograph position that changes in time. Fig. 7 shows the time histories generated for the track stiffness discontinuity of type 1, while Fig. 8 is related to discontinuity of type 2. As previously, the location of the track stiffness discontinuity is indicated by a dotted vertical green line. As a reference, the corresponding time histories obtained without taking the vehicle body vibrations into account are shown. All graphs illustrate the same fragment of time histories, where the pantograph moves along the third, fourth, and half of the fifth span.

The obtained results demonstrate that the vehicle body vibrations induced by crossing the track stiffness discontinuity do not considerably influence the catenary vibrations. Differences between time histories of the contact wire uplift are almost unnoticeable. In case of the dynamic contact force, the influence of vehicle body vibrations is more noticeable, but it is relevant only in oneload scenario, in which the train without the secondary suspension passes the track stiffness discontinuity of type 1 at the speed of $100 \mathrm{~m} / \mathrm{s}$ (Fig. 8). Under these conditions, an additional peak of the contact force oscillation is

Table 2: Catenary and pantograph parameters.

\begin{tabular}{|c|c|c|c|}
\hline Messenger wire specific mass & $1.07 \mathrm{~kg} / \mathrm{m}$ & Mass of the pantograph collector head & $7.2 \mathrm{~kg}$ \\
\hline Messenger wire tension & $16 \mathrm{kN}$ & Mass of the pantograph articulated frame & $15.0 \mathrm{~kg}$ \\
\hline Messenger wire axial stiffness & $12 \mathrm{MN}$ & Pantograph static force & $120 \mathrm{~N}$ \\
\hline Contact wire specific mass & $1.35 \mathrm{~kg} / \mathrm{m}$ & Stiffness of the upper spring of the pantograph & $4200 \mathrm{~N} / \mathrm{m}$ \\
\hline Contact wire tension & $20 \mathrm{kN}$ & Stiffness of the lower spring of the pantograph & $50 \mathrm{~N} / \mathrm{m}$ \\
\hline Dropper tensile stiffness & $100 \mathrm{kN} / \mathrm{m}$ & $\begin{array}{l}\text { Parameter of the upper damper of the } \\
\text { pantograph }\end{array}$ & $10 \mathrm{Ns} / \mathrm{m}$ \\
\hline Single span length & $60 \mathrm{~m}$ & $\begin{array}{l}\text { Parameter of the lower damper of the } \\
\text { pantograph }\end{array}$ & $90 \mathrm{Ns} / \mathrm{m}$ \\
\hline Number of droppers within span & 9 & Stiffness of the contact spring & $50 \mathrm{kN} / \mathrm{m}$ \\
\hline Material damping coefficient of the messenger wire & $0.5 \%$ & Material damping coefficient of the contact wire & $0.5 \%$ \\
\hline
\end{tabular}




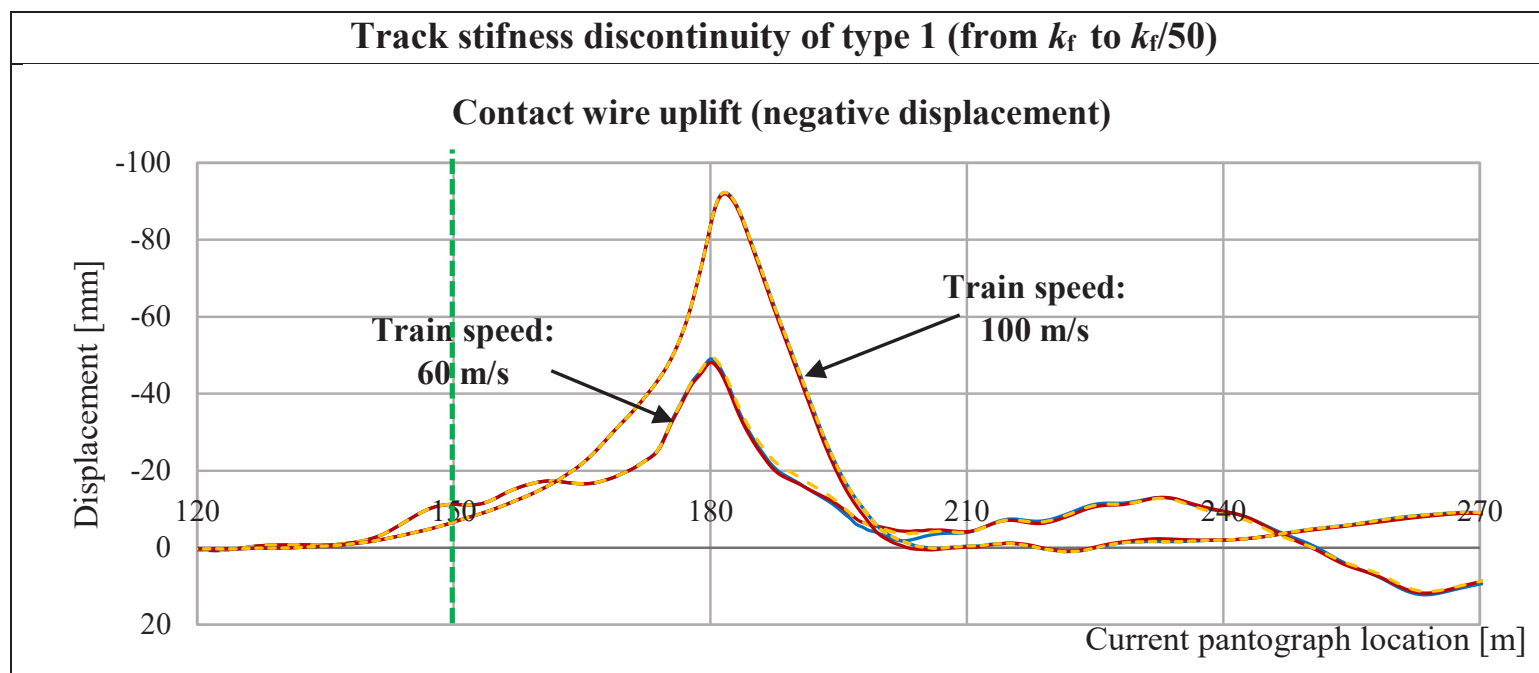

Train speed: $60 \mathrm{~m} / \mathrm{s}$

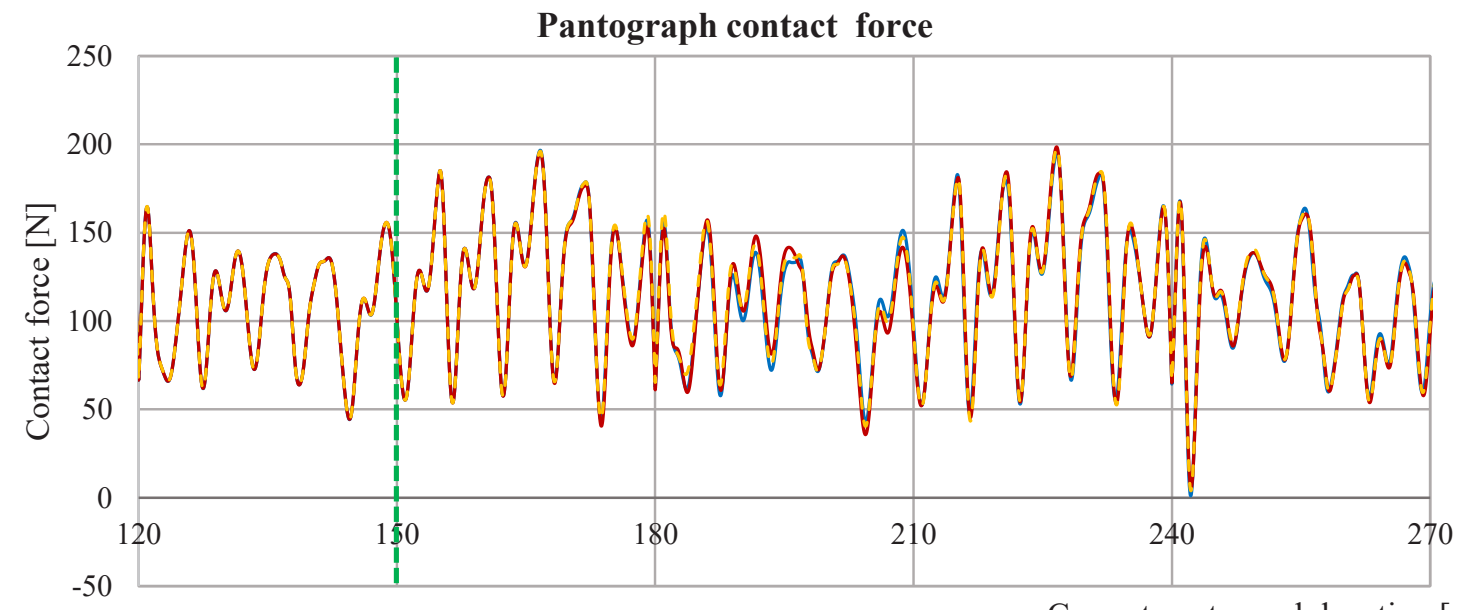

Current pantograph location $[\mathrm{m}]$

\section{Train speed: $100 \mathrm{~m} / \mathrm{s}$}

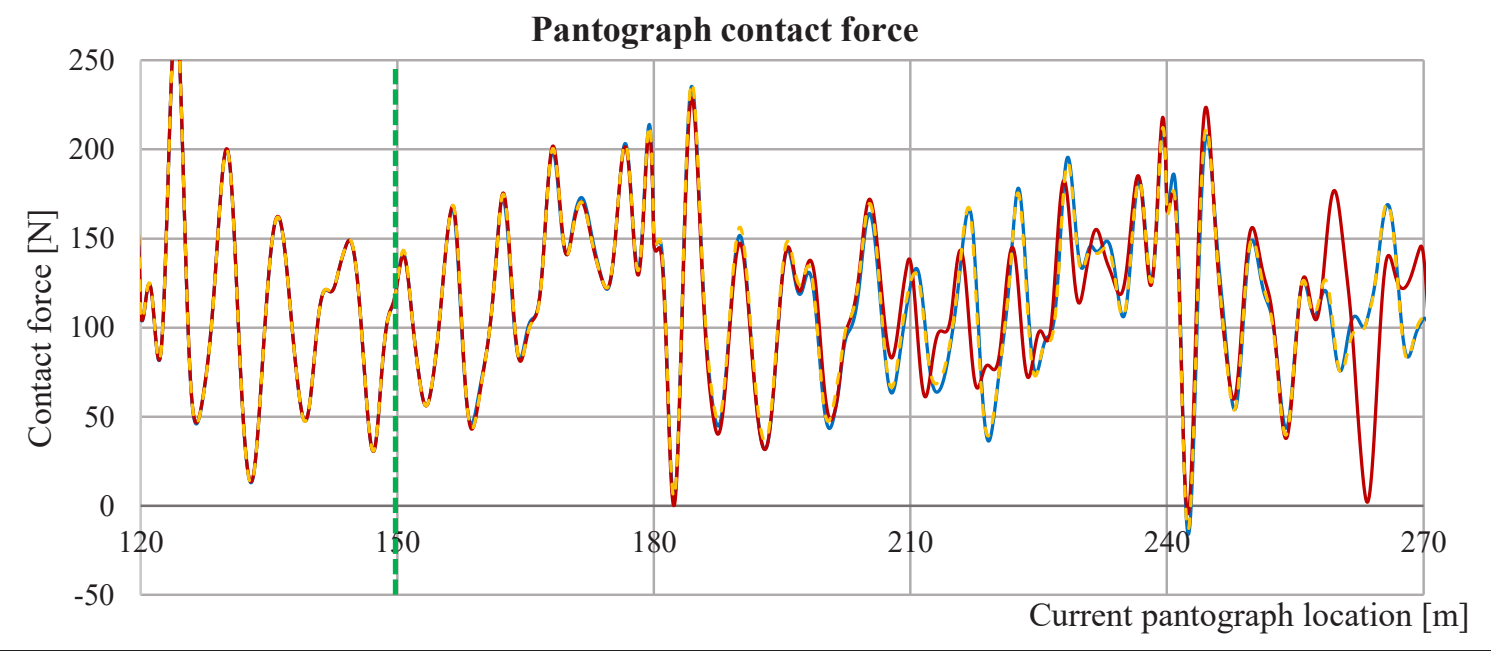

Figure 7: Contact wire uplift at the right steady arm of the middle catenary span and the pantograph contact force, computed under the following conditions: yellow color line indicates a case when vehicle vibrations are not taken into account, blue color line indicates vehicle with two-stage suspension, and red color line indicates vehicle without secondary suspension. 


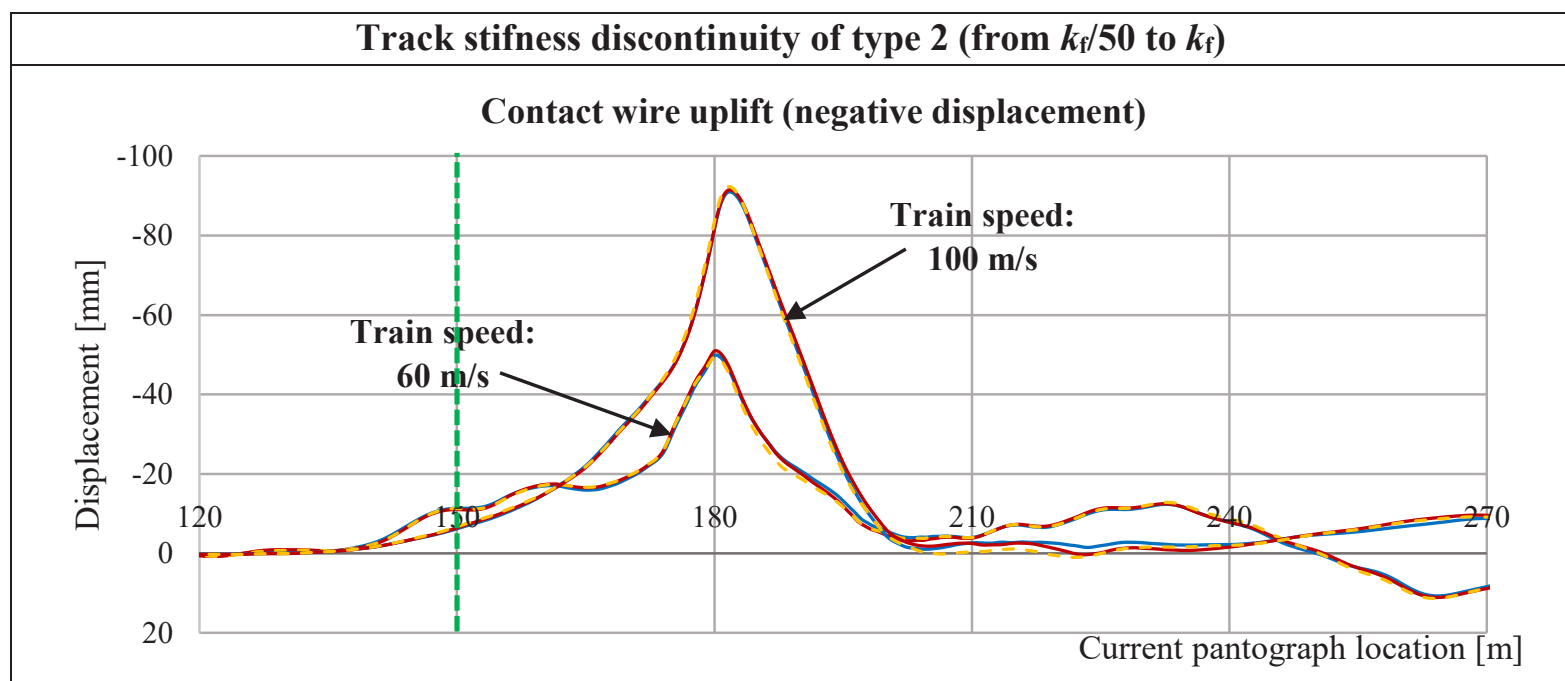

Train speed: $60 \mathrm{~m} / \mathrm{s}$

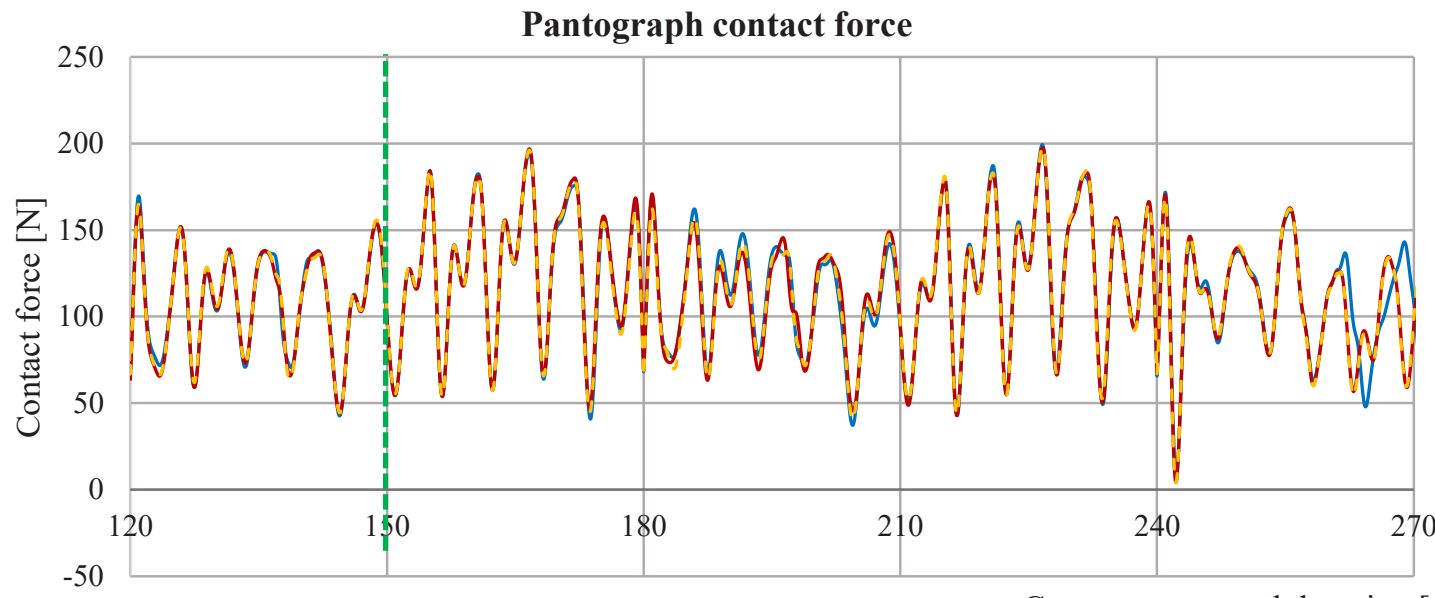

Current pantograph location [m]

Train speed: $100 \mathrm{~m} / \mathrm{s}$

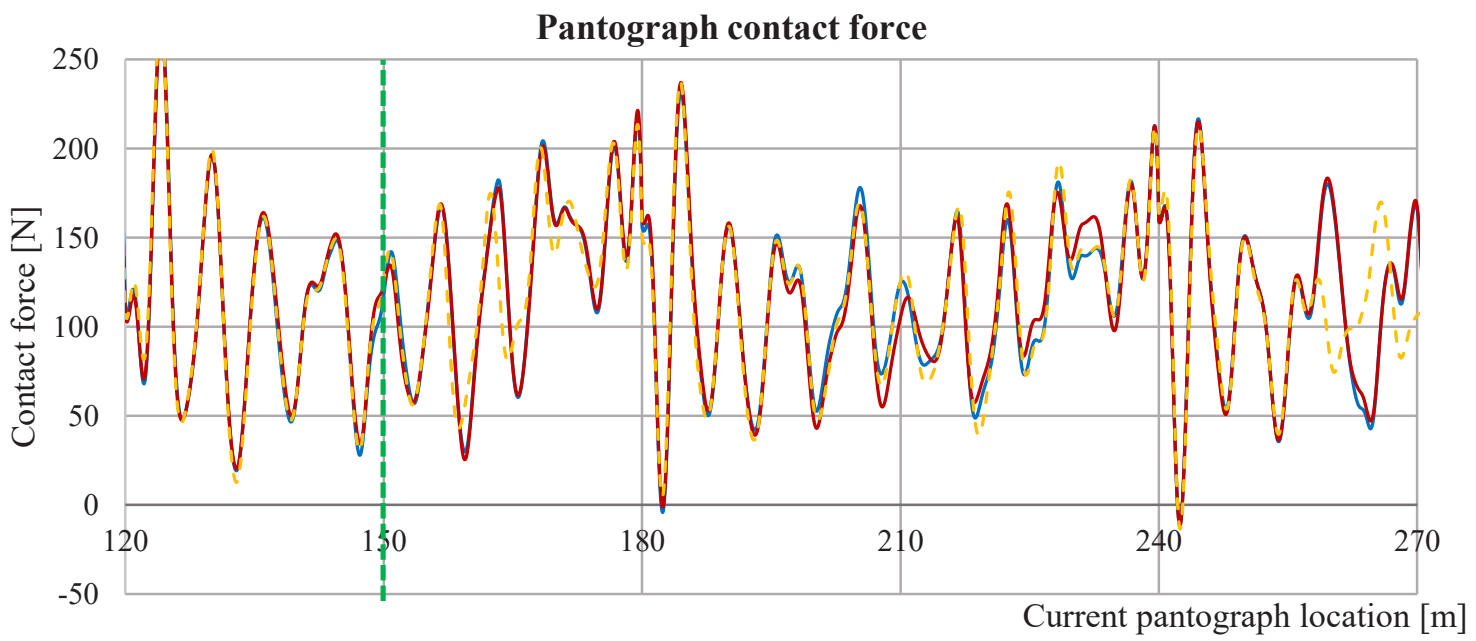

Figure 8: Contact wire uplift at the right steady arm of the middle catenary span and the pantograph contact force, computed under the following conditions: yellow color line indicates a case when vehicle vibrations are not taken into account, blue color line indicates vehicle with two-stage suspension, and red color line indicates vehicle without secondary suspension. 
observed in the last phase of the pantograph run (from $240 \mathrm{~m}$ to $270 \mathrm{~m}$ ), which leads to a strong local decrease in the contact force and thus to loss of contact (the loss of contact occurs when the contact force is zero or negative). It means that the railway vehicle vibrations might increase the probability of loss of contact between pantograph head and contact wire, but the two-stage suspension used in high-speed trains effectively prevents such incidents.

\section{Conclusions}

In this article, the research methodology of the catenarytrain-track system vibration analysis is presented and used to estimate the influence of vehicle body vertical motion on the pantograph-catenary dynamic interaction. This issue is rarely referred in the literature, although any perturbations appearing at the pantograph-catenary interface are of great importance for the operation of highspeed trains because they may lead to loss of contact and thus to energy supply disruption. It follows from the literature that the geometrical irregularities of the track have a small effect on the quality of pantograph-catenary dynamic interaction [11]. Therefore, another problem was considered in this article. To find a train passage scenario that may worsen the operational conditions at the pantograph-catenary interface, the track stiffness discontinuity being the most frequent cause of significant vehicle vibration has been analyzed.

The numerical analysis of vibrations of the catenarytrain-track system, presented in this article, leads to the conclusion that in the case of high-speed trains with typical two-stage suspension, the vehicle body vibrations induced by a sudden 50 -fold change in the track stiffness do not transfer to the catenary and do not significantly affect the pantograph-catenary dynamic interaction. It was demonstrated that the efficiency of the twostage suspension increases with the train speed; hence, such vehicle suspension effectively suppresses strong sudden shocks of the vehicle body appearing while the train passes through the track stiffness discontinuity at a high speed. It was also shown that removing the secondary vehicle suspension significantly changes a vehicle dynamic response. Vibrations of the pantograph base mounted on vehicle roof are more clearly of impulse response nature and are characterized by much higher accelerations. The intensity of this dynamic effect increases with the train speed. Even in this case, vehicle vibrations do not influence the dynamic displacements of the catenary. However, their impact on the contact force exerted on the overhead contact line by the pantograph head is observable. It was demonstrated that in the case of using the one-stage suspension in the train running at high speed, pantograph base vibrations may increase the number of contact loss events being highly undesirable due to the occurrence of electric arcing that causes surface damages of the contact wire and pantograph head strips.

It should be emphasized that the presented numerical analysis of the overhead contact line vibrations was limited only to displacement analysis although, in the considered case, the kinematic excitation of the pantograph vibrations is manifested mainly in accelerations. Considering that a train passage through the track stiffness discontinuity results in vehicle body vibrations of fairly small amplitudes of displacements and significant acceleration amplitudes, it can be supposed that a similar effect may exist in catenary vibrations. It means that the track stiffness discontinuity influence may be more apparent in accelerations of catenary vibrations than in the displacements, just like in the case of the vehicle body. This problem will be the subject of further research, which will be possible after supplementing the vibration simulation method of the catenary-pantograph subsystem with the option for calculating the vibration accelerations.

\section{References}

[1] Zhai, W., Wang, K., Cai, C. (2009). Fundamentals of vehicletrack coupled dynamics. Vehicle System Dynamics, 47(11), 1349-1376.

[2] Galvín, P., Romero, A., Domínguez, J. (2010). Vibrations induced by HST passage on ballast and non-ballast tracks. Soil Dynamics and Earthquake Engineering, 30, 862-873.

[3] Yang, X., Gu, S., Zhou, S., Yang, J., Zhou, Y., Lian, S. (2015). Effect of track irregularity on the dynamic response of a slab track under a high-speed train based on the composite track element method. Applied Acoustics, 99, 72-84.

[4] Cho, Y. H. (2008). Numerical simulation of the dynamic responses of railway overhead contact lines to a moving pantograph, considering a nonlinear dropper. Journal of Sound and Vibration, 315, 433-454.

[5] Cho, Y. H., Lee, K., Park Y., Kang, B., Kim, K. (2010). Influence of contact wire pre- sag on the dynamics of pantograph-railway catenary. International Journal of Mechanical Sciences, 52, 1471-1490.

[6] Massat, J-P., Laurent, C., Bianchi, J-P., Balmès, E. (2014). Pantograph catenary dynamic optimisation based on advanced multibody and finite element co-simulation tools. Vehicle System Dynamics, 52(Supplement), 338-354.

[7] Ambrósio, J., Pombo, J., Pereira, M., Antunes, P. and Mósca, A. (2012). Recent developments in pantograph-catenary 
interaction modelling and analysis. Journal of Theoretical and Applied Mechanics, 1(1), 249-278.

[8] Ambrósio, J., Pombo, J., Pereira, M., Antunes, P., Mósca, A. (2012). A computational procedure for the dynamic analysis of the catenary-pantograph interaction in high- speed trains. Journal of Theoretical and Applied Mechanics, 50(3), 681-699.

[9] Pombo, J., Antunes, P., Ambrósio, J. (2012). A study on multiple pantograph operations for high-speed catenary contact. In B. H. V. Topping (Ed.), Proceedings of the Eleventh International Conference on Computational Structures Technology (paper 139). Stirlingshire, Scotland: Civil-Comp Press.

[10] Poetsch G., Evans J., Meisinger R., Kortüm W., Baldauf W., Veitl A., Wallaschek J. (1997). Pantograph/catenary dynamics and control. Vehicle System Dynamics, 28, 159-195.

[11] Pombo, J., Ambrosio, J. (2013). Environmental and track perturbations on multiple pantograph interaction with catenaries in high-speed trains. Computers and Structures, 124, 88-101.

[12] Bryja, D., Popiołek (Hyliński), A. (2017). Analiza drgań wieszara cięgnowego jako modelu kolejowej sieci trakcyjnej obciążonej ruchem pantografów. Journal of Civil Engineering, Environment and Architecture, 34(2), 177-190.

[13] Bryja, D., Prokopowicz, D. (2016). Dyskretno-ciągty model obliczeniowy sprzężonego układu dynamicznego: pantograf - napowietrzna sieć trakcyjna. Przegląd Komunikacyjny. 71(5), 44-51.

[14] Bryja, D., Hyliński, A. (2019). Droppers' stiffness influence on dynamic interaction between the pantograph and railway catenary. Railway Reports, 63(183), 89-98.

[15] Bryja, D., Popiołek (Hyliński), A. (2018). Numeryczna symulacja drgań sieci trakcyjnych na liniach KDP, z uwzględnieniem nieliniowej pracy linek wieszakowych. In P. Kozioł, A. Szarata \& W. Drozd (Eds.), Inżynieria kolejowa - szanse i wyzwania (pp. 55-76). Kraków, Poland: Wydawnictwo Politechniki Krakowskiej.

[16] CENELEC. (2002). EN 50318:2002 Railway applications Current collection systems -Validation of simulation of the dynamic interaction between pantograph and overhead contact line. Brussels: Central Secretariat of European Committee for Electrotechnical Standardization.

[17] Bryja, D., Gisterek, I., Popiołek (Hyliński), A. (2015). Analiza numeryczna wpływu nierówności progowej na drgania toru kolejowego spowodowane przejazdem pociągu dużych prędkości. Inżynieria i Budownictwo, 71(10), 532-536.

[18] Bryja, D. Popiołek (Hyliński), A. (2015). Analiza drgań pojazdów kolejowych w trakcie ich przejazdu przez nierówność progową toru. Przegląd Komunikacyjny, 70(9), 68-72.

[19] Bryja, D., Popiołek (Hyliński), A. (2018). Drgania sieci trakcyjnej spowodowane przejazdem pociągu dużych prędkości przez nierówność progową toru kolejowego. Przegląd komunikacyjny, 73(6), 7-12.

[20] Benra, F. K., Dohmen, H. J., Pei, J., Schuster, S., \& Wan, B. (2011). A comparison of one-way and two-way coupling methods for numerical analysis of fluid-structure interactions. Journal of Applied Mathematics, 2011, doi:10.1155/2011/853560.

[21] Esveld, C. (2014). Modern Railway Track. Zaltbommel: MRTProductions.

[22] Bryja, D., Gisterek, I., Popiołek (Hyliński), A. (2015). A computational method for acceleration analysis of a railway track with a stiffness discontinuity. In J. Kruis, Y. Tsompanakis \& B.H.V. Topping (Eds.), Proc. of the Fifteenth Int. Conf. on Civil, Structural and Environmental Engineering Computing, Prague - Czech Republic, 1-4 September 2015, (pp. 1-13). Stirlingshire, Scotland: Civil-Comp Press.

[23] Bryja, D., Hołubowski, R., Gisterek, I. (2014). Railroad vehicle modelling in probabilistic vibration analysis of a railway bridge with randomly fluctuating track ballast stiffness. In A. Cunha et al (Eds.), Proc. of the Ninth European Conference on Structural Dynamics EURODYN 2014, Porto - Portugal, 30 June - 2 July, (pp. 2737-2744). Porto: Clássica, Artes Gráficas. 